\title{
ASSOCIATIONS BETWEEN COGNITIVE DISTORTIONS IN MORAL REASONING AND SELF-REPORTED TRAFFIC VIOLATIONS AND CRASHES FOR DIFFERENT ROAD USER GROUPS
}

\author{
Erik Roelofs ${ }^{1}$, Pierro Hirsch ${ }^{2}$, Jan Vissers ${ }^{3}$ \\ Cito $^{1}$, Arnhem, THE NETHERLANDS, Virage Simulation ${ }^{2}$, Montreal, Canada \\ Royal Haskoning DHV $^{3}$, Amersfoort, The Netherlands \\ Email: Erik.Roelofs@cito.nl
}

\begin{abstract}
Summary: The use of self-serving cognitive distortions measured by traffic-role specific versions of the Cognitive Distortions in Driving (CDD) test was explored for three Dutch road user groups: cyclists beginning to learn to drive (LDs) who were enrolled in a pro-social driving program $(\mathrm{n}=138)$; young novice drivers enrolled in a safety awareness program $(\mathrm{n}=1660)$, and; experienced professional bus drivers enrolled in a post-licensing training program (871). Associations between cognitive distortions and self-reported traffic behavior, fines and crashes were analyzed. Results show that about 20 per cent of the young novice drivers used self-serving cognitive distortions, compared to 8 per cent of the LDs and 5 per cent of the bus drivers. In addition, use of cognitive distortions was significantly correlated with speed and traffic violations. Finally, a subgroup of cyclist LDs $(\mathrm{n}=38)$ who had been licensed for six months used fewer cognitive distortions when tested as drivers than the licensed young novice drivers without pro-social driver training. This shows that pro-social driver training can reduce cognitive distortions and may possibly increase safety.
\end{abstract}

\section{INTRODUCTION}

Contemporary views on driver training recognize that vehicle control skills (e.g. steering and braking) may be less important for safety than higher order skills. Higher order skills are the cognitions and metacognitions that enable drivers to perceive and mitigate hazards in complex traffic situations and also include socio-moral influences that increase road sharing behavior and compliance with traffic rules. Lower levels of socio-moral competence, as reflected by anti-social and aggressive driving behavior, were associated with risky driving behaviors (Gidron, et al., 2015). Crash risk reductions have been observed after interventions that focus on the higher order skills of situational awareness and self-evaluation (Isler, Starkey, \& Sheppard, 2011, Beanland, Goode, Salmon, \& Lenné, 2013) and resilience training against peer pressure to drive unsafely (Senserrick et al., 2009). One aspect of resilience training aims at reducing cognitive distortions about one's own driving behavior.

Gibbs (2003) defines cognitive distortions as inaccurate or rationalizing attitudes, thoughts, or beliefs concerning own or other's behavior and he distinguishes four types (See Table 1). In the context of juvenile delinquency it was found that cognitive distortions are positively associated with self-reported antisocial behavior (Barriga et al., 2001). Recent studies in juvenile delinquency indicate that certain types of cognitive distortions can be addressed effectively within dedicated training programs (Van Stam et al., 2014). 
Table 1. Four types of cognitive distortions (Gibbs, 2003)

\begin{tabular}{ll}
\hline Type & Description \\
\hline 1. Self-centered reasoning & $\begin{array}{l}\text { Attributes predominance to one's own views to the exclusion of the legitimate views or } \\
\text { needs of others } \\
\text { 2. Blaming others }\end{array}$ \\
$\begin{array}{l}\text { Misattributes responsibility to outside sources, especially other persons, group, or unusual } \\
\text { events }\end{array}$ \\
$\begin{array}{l}\text { Depicts antisocial behavior as harmless, acceptable or admirable, or belittles or } \\
\text { dehumanizes others } \\
\text { Gratuitously attributes hostile intentions to others or assumes the inevitability of worst- } \\
\text { case scenarios for social situations, or the impossibility of improvements in one's own or } \\
\text { others' behavior }\end{array}$ \\
\hline
\end{tabular}

Based on these promising results it is expected that pro-social driving behavior can be increased through training (Van Stam et al., 2014). Recently, training in socio-moral thinking has been considered as an addition to Dutch driver training programs in order to promote prosocial driving behaviors, including accepting personal responsibility for the safety of other road users. This study focuses on an important variable of socio-moral competence, the degree to which drivers use cognitive distortions. Associations between cognitive distortions, selfreported driving behavior, and driving violations were studied for three groups of traffic participants: cyclists who are beginner learner drivers (LDs); young novice drivers, and; experienced professional bus drivers. Three research questions were addressed. First, to what extent do traffic participants in different roles report self-serving cognitive distortions in traffic? Second, to what extent is the use of self-serving cognitive distortions related to selfreported driving behavior, including speed choice, rule compliance, fines and crashes? Finally, can the use of cognitive distortions be influenced by pro-social driving training?

\section{METHOD}

\section{Subjects}

The data for the road user groups in this study were drawn from the populations of three different research projects. The cyclist/beginner learner driver (LD) group consisted of 133 participants (mean age at start of training: 18.4 years, mean license age: 19.1 years, 45 per cent male) enrolled in a driving intervention known as Developmentally Adapted Driver Education (DADE), between fall 2016 and spring 2018. Due to time constraints, only 38 participants from this group were followed up as drivers six months after licensing (Roelofs \& Vissers, 2017). DADE was financed by the Province of North Limburg and consisted of a four-stage, 60-hour long driver-training program. Participants learned vehicle handling and higher order driving skills and were encouraged to adopt pro-social driving styles, including empathizing with other road users and making decisions that consider the safety and flow of all road users within the traffic system. DADE participants filled out the CDD before the program $(n=133)$ from the perspective of a cyclist and half a year after licensure from the perspective of a driver $(\mathrm{n}=38)$.

The young novice driver group consisted of 1660 respondents (mean age: 19.8 years, mean license age: 18.7 years, 52.3 per cent male) from different educational backgrounds enrolled in the DriveXperience-program (DX) from fall 2014 to fall 2016. They came from 62 Dutch municipalities and participated on a voluntary basis. The DX program consisted of a half-day 
safety awareness training on the road, on a track, and during a workshop. Before the start of the program day, DX-participants filled out the CDD from the perspective of a driver. On average, 75 per cent of the originally 2213 participants responded to the invitation to complete the CDD.

The professional bus driver group consisted of 871 employees (mean age: 49.7 years, 84.2 per cent male) of a large Dutch bus company. The company drivers took part in an eight-hour coaching program aimed at defensive driving, partly on the road and partly in group workshops in the period between spring 2016 and spring 2017. By attending the program, drivers complied with a European directive that requires bus drivers to take training every five years to keep their professional driver license. Before the start of the program, 95 per cent of 942 participating bus drivers completed the CDD from the perspective of a driver.

\section{Instrumentation and data collection}

In 2015, the Cognitive Distortions in Driving (CDD) test was developed, inspired by the original How I Think Questionnaire (Gibbs, Barriga, and Potter, 2001). The CDD consists of 43 items administered online (Roelofs \& Hirsch, 2017) that measure the association between drivers' self-serving cognitive distortions and their socially undesirable driving behavior. An example of an item for "self-centered reasoning" is: "When I have to arrive at a meeting on time, I allow myself to drive faster than the speed limit." An example of "blaming others" is: "I tailgate on the highway because other vehicles do not move through the traffic quickly enough." An example of minimizing/mislabeling is: "If I return to my car quickly, it is okay to park in a restricted area." An example of "assuming the worst" is: "When I want to merge with traffic, other road users do not let me in voluntarily". For all items the driver responded on a six-point Likert scale ranging from 'disagree strongly' to 'agree strongly'. The original CDD was given to the young novice drivers. Two adapted versions of the CDD were given to cyclists and bus drivers respectively. Each adapted version contained new items developed in cooperation with training experts for each group. The cyclist version, aimed to assess beginner learner drivers' baseline use of cognitive distortions was developed in 2015 and contained items describing interactions with cars and with pedestrians. The bus driver version developed in 2016 contained items adapted to address professional responsibilities for passenger safety and comfort. The new items represented typical cyclist or bus driver situations. An example of a reworded item for bus driver "self-centered reasoning" is, "If I want to make up lost time, I allow myself to drive past bus stops where passengers are waiting".

All three CDD versions included questions about background variables, i.e. age, gender, highest attained level of education, years of experience on various vehicles, and driving behavior, i.e. annual mileage, speed choice, crashes, and fines. For all drivers, preferred driving speeds pertained to roads with posted limits of $30 \mathrm{~km} / \mathrm{h}, 50 \mathrm{~km} / \mathrm{h}, 80 \mathrm{~km} / \mathrm{h}$, and 120 $\mathrm{km} / \mathrm{h}$. Bus drivers were questioned about the roads they most frequently used during their service hours with posted limits of $30 \mathrm{~km} / \mathrm{h}, 50 \mathrm{~km} / \mathrm{h}$ and $60 \mathrm{~km} / \mathrm{h}$. In all cases, the speed choices were asked in reference to the following conditions: a) quiet traffic; b) busy traffic, and; c) rainy weather. Young novice drivers and bus drivers were asked how many fines they had received during the past year for each of ten common types of traffic violations including not wearing seat belts, speeding, and making hand-held phone calls. All respondents were asked whether they had received vehicle-specific fines. For example, bus drivers may have too 
many passengers on board or may drive in a bus lane during off-duty hours. Car drivers may speed on a motorway or park illegally. Beginner learner drivers were asked how often they had committed each of 15 common traffic violations as a cyclist during the year before their driver training started, for example not yielding to other road users; running a red light; cycling with defective lights; drink and ride. Young novice drivers and beginner learner drivers who had licensed after the DADE program were asked about 15 similar common traffic violations as a driver, such as drinking and driving and speeding. The bus drivers were not questioned about traffic violations due to questionnaire length limitations set by the training consortium.

\section{RESULTS}

Table 2 shows psychometric properties and means expressed on a scale from 0 to 100 for Cognitive Distortions for the three groups. A higher score represents a more frequent use of a distortion. For each distortion subscale a cut score procedure, described in Roelofs \& Hirsch (2017), was applied to determine whether individual respondents would likely use a cognitive distortion. Thus it can be observed that around 20 per cent of the young novice drivers engaged in self-serving cognitive distortions, compared to only 5 per cent of the bus drivers and 8 per cent of the LDs. The differences between the groups in the frequencies of respondents that use cognitive distortions are significant $\left(\chi^{2}=13.0, d f=3, p<.001 ; \chi^{2}=104.8\right.$, $d f=3, p<.001$ respectively). Compared to bus drivers, young novice drivers more frequently use all four types of cognitive distortions. Chi-square values range between 69 and 104 (for all: $d f=3, p<.001)$. The percentages of cyclists that minimize or mislabel $\left(\chi^{2}=.31, d f=3, p=.58\right)$ and assume the worst $\left(\chi^{2}=.63, d f=3, p=.42\right.$ ) do not differ from those of young novice drivers. However, cyclists use self-centered reasoning and blaming others far less frequently than young novice drivers (respective values: $\chi^{2}=.13 .82, d f=3, p<.001 ; \chi^{2}=21.64, d f=3, p<.001$ ).

Table 3 shows partial correlations between Cognitive Distortions and driving behavior variables. After controlling for age, education and mileage significant positive correlations are found between cognitive distortions and driving speed for bus drivers $(r=.41 ; p<.01)$ and young novice drivers $(r=.42 ; p<.01)$. In addition, Cognitive Distortions are significantly correlated with traffic violations, both for beginner learner drivers based on their behavior as cyclists $(r=.46, p<.001)$ and for young novice drivers $(r=.54 ; p<.001)$. The correlations between Cognitive Distortions and fines were non-significant for young novice drivers $(r=.07 . \mathrm{p}=.06)$ and significant for bus drivers $(r=.13, p<.001)$, after controlling for age, educational level, mileage and speed. The correlations between Cognitive Distortions and crashes were not significant for any of the groups after controlling for age, education, mileage and speed.

Table 4 shows the mean scores on Cognitive Distortions prior to the DADE program in the role of cyclists and six months after licensing, both for a part of the DADE beginner learner drivers group and for the young novice drivers. Note that the DADE-group with six months of driving experience scored significantly lower than the licensed novice drivers on three out of four types of cognitive distortions. Effect sizes range between -.30 and -.57. In addition, the DADE-group use of Minimizing decreased significantly, while the use of Blaming others and Assuming the worst remained stable. Self-centered reasoning increased significantly, but the level was still below that of the young novice drivers group. 
PROCEEDINGS of the Tenth International Driving Symposium on Human Factors in Driver Assessment, Training and Vehicle Design

Table 2. Cognitive distortions in moral reasoning about own undesirable behavior by traffic role

\begin{tabular}{|c|c|c|c|c|c|c|c|c|c|}
\hline \multirow[b]{2}{*}{$\begin{array}{l}\text { Subscales Cognitive } \\
\text { Distortions }\end{array}$} & \multirow[b]{2}{*}{ Group } & \multicolumn{7}{|c|}{ Scale statistics } & \multirow{2}{*}{$\begin{array}{c}\begin{array}{c}\text { Percentage } \\
\text { respondents } \\
\text { that likely use } \\
\text { cognitive } \\
\text { distortions }\end{array} \\
\%\end{array}$} \\
\hline & & $\begin{array}{l}\text { Nof } \\
\text { Items }\end{array}$ & $\begin{array}{l}\text { Alpha } \\
\text { scale }\end{array}$ & $\mathbf{N}$ & Mean & SD & Min & $\max$ & \\
\hline \multirow{3}{*}{$\begin{array}{l}\text { Self-centered } \\
\text { reasoning }\end{array}$} & 1: Beginner learner drivers & 8 & .82 & 133 & 12.7 & 12.1 & 0.0 & 80.0 & $4 \%$ \\
\hline & 2: Young novice drivers & 9 & .70 & 1660 & 24.5 & 12.4 & 0.0 & 73.3 & $16 \%$ \\
\hline & 3: Bus drivers & 10 & .80 & 808 & 12.6 & 12.1 & 0.0 & 100.0 & $3 \%$ \\
\hline \multirow[t]{3}{*}{ Blaming others } & 1: Beginner learner drivers & 8 & .78 & 133 & 23.3 & 14.7 & 0.0 & 65.0 & $5 \%$ \\
\hline & 2: Young novice drivers & 10 & .80 & 1660 & 33.5 & 15.1 & 0.0 & 88.0 & $22 \%$ \\
\hline & 3: Bus drivers & 9 & .78 & 808 & 24.1 & 15.0 & 0.0 & 100.0 & $7 \%$ \\
\hline \multirow{3}{*}{$\begin{array}{l}\text { Minimizing/ } \\
\text { mislabeling }\end{array}$} & 1: Beginner learner drivers & 7 & .82 & 133 & 21.5 & 14.4 & 0.0 & 71.4 & $22 \%$ \\
\hline & 2: Young novice drivers & 9 & .73 & 1660 & 22.8 & 13.2 & 0.0 & 91.1 & $20 \%$ \\
\hline & 3: Bus drivers & 11 & .79 & 808 & 15.1 & 12.3 & 0.0 & 100.0 & $7 \%$ \\
\hline \multirow[t]{3}{*}{ Assuming theworst } & 1: Beginner learner drivers & 7 & .78 & 133 & 24.1 & 15.6 & 0.0 & 74.3 & $20 \%$ \\
\hline & 2: Young novice drivers & 8 & .68 & 1660 & 29.5 & 13.8 & 0.0 & 87.5 & $23 \%$ \\
\hline & 3: Bus drivers & 8 & .74 & 808 & 20.7 & 13.8 & 0.0 & 100.0 & $7 \%$ \\
\hline Overall scale & 1: Beginner learner drivers & 30 & .92 & 133 & 20.2 & 11.9 & 0.0 & 72.0 & $8 \%$ \\
\hline \multirow[t]{2}{*}{ Cognitive Distortions } & 2: Young novice drivers & 36 & .91 & 1660 & 26.5 & 11.4 & 0.0 & 74.2 & $21 \%$ \\
\hline & 3: Bus drivers & 38 & .93 & 865 & 17.5 & 11.6 & 0.0 & 100.0 & $5 \%$ \\
\hline
\end{tabular}

Note * For cut-off scores used see Roelofs \& Hirsch (2017)

Table 3. Partial correlations between Cognitive Distortions and driving behavior variables

\begin{tabular}{lccc}
\hline & Beginner learner drivers & Young novice drivers & Bus drivers \\
\hline $\begin{array}{l}\text { 1. Reported driving speed } \\
\text { 2. Reported frequency of committed traffic }\end{array}$ & NA & $.42^{* *}$ & $.41^{* *}$ \\
violations & $.46^{* *}$ & $.54^{* *}$ & NA \\
3. Reported number of fines & NA & .01 & $.13^{* *}$ \\
4. Reported number of crashes & NA & .07 & .07 \\
\hline
\end{tabular}

Note $* *=p<.01$

Table 4. Cognitive distortions before training and six months after licensing

\begin{tabular}{lccccccc}
\hline & \multicolumn{2}{c}{$\begin{array}{c}\text { DADE-group beginner learner drivers } \\
(\mathrm{n}=38)\end{array}$} & \multicolumn{3}{c}{$\begin{array}{c}\text { Non-trained Young novice } \\
\text { drivers }(\mathrm{n}=1660)\end{array}$} \\
\hline & $\begin{array}{c}\text { Pretest: as a } \\
\text { Cyclist }\end{array}$ & $\begin{array}{c}\text { Posttest: as a } \\
\text { driver }\end{array}$ & \multicolumn{2}{c}{ Post-test only } \\
\hline & Mean (SD) & Mean (SD) & D within & $t$ & Mean (SD) & $\begin{array}{c}\text { D } \\
\text { between }\end{array}$ & $t$ \\
\hline Self-centered reasoning & $11.2(12.0)$ & $20.7(12.4)$ & -.59 & $-4.59^{* *}$ & $24.5(12.4)$ & -.30 & 1.83 \\
Blaming others & $22.1(15.2)$ & $24.9(12.4)$ & -.35 & -0.97 & $33.5(15.1)$ & -.57 & $3.23^{* *}$ \\
Minimizing/mislabeling & $22.0(14.7)$ & $16.0(15.2)$ & .66 & $2.78^{* *}$ & $22.8(13.2)$ & -.51 & $2.74^{* *}$ \\
Assuming the worst & $23.0(15.9)$ & $22.1(17.3)$ & -.07 & 0.33 & $29.5(13.8)$ & -.53 & $2.61^{* *}$ \\
\hline
\end{tabular}

\section{DISCUSSION}

Literature on juvenile crime consistently shows associations between the use of self-serving cognitive distortions and involvement in anti-social behavior (Barriga, Morrison, Liau, \& Gibbs, 2001). Cognitive distortions are assumed to block moral judgment development because one does not consider oneself responsible for one's anti-social behavior. Cognitive distortions are also associated with anti-social driving behavior (Gidron, et al., 2015). This study investigated the prevalence of cognitive distortions and the relationship between cognitive distortions in moral reasoning and self-reported driving behavior, traffic violations and crashes. Based on the 'How I Think' questionnaire developed by Gibbs, three contextspecific versions of the Cognitive Distortions in Driving test were developed to measure four 
types of cognitive distortions used when driving or cycling.

Results regarding the prevalence of cognitive distortions (research question 1) showed that compared to recently licensed young novice drivers and beginner young drivers in the role of cyclists, bus drivers engage much less frequently in cognitive distortions (around five per cent). Beginner learner drivers (DADE-group) in the role of cyclists use fewer cognitive distortions (eight percent) than the licensed young novice drivers (around 20 per cent). Results regarding the association between cognitive distortions and driving (research question 2) were as expected. Overall, the prevalence of self-serving cognitive distortions regarding anti-social driving behavior appeared to be significantly correlated with the frequency of traffic violations for all three groups and with driving at higher speeds for novice young drivers and bus drivers. No significant correlations were found between cognitive distortions and crashes. Finally, the results show that the use of cognitive distortions can be positively influenced by pro-social driver training (research question 3). Recently licensed participants in the DADE program showed lower levels of cognitive distortions than the reference group of DX-participants without pro-social driver training. In addition, within the DADE-group self-centered reasoning increased in use as compared to the role as a cyclists, whereas the use of minimizing decreased, and the use of blaming others and assuming the worst remained at the same level.

Several possible explanations for the higher percentage of cognitive distortions among novice drivers compared to cyclists. One possible explanation relates to Concern Theory, originally developed by Fuller (1969), which describes the cycle of concerns novice professionals go through when they first independently apply complex skills in practice. The theory explained how first-year teachers are usually self-concerned, worrying about surviving their first lessons. This self-concern may result in misattributions about classroom problems, e.g. attributing the cause to difficult students. With experience, teachers become more concerned about achieving professional standards and about impact on students. Given the greater risks of harming others while driving a car compared to cycling, a temporary period of self-concern may explain the self-centered reasoning of young drivers.

Another possible explanation for the higher percentage of cognitive distortions among novice young drivers compared to cyclists may be a regression in sociomoral competence due to lack of preparation for novel social situations such as new travel purposes and driving with peers. Lind (2002) found evidence that students, due to the absence of dedicated educational programs, can regress to an earlier stage of moral competence where their capacity to make decisions and judgments based on moral principles is diminished.

This study has several limitations. The self-reported data might introduce under-reporting of cognitive distortions, traffic fines and crashes. The size of the sub-group of learner drivers who licensed within the limits of the data collection period was too small to permit confident conclusions. Finally, there may have been a self-selection bias even though the novice driver group did not differ from the learner drivers regarding age, mileage and driving experience.

The results from this study suggest that addressing cognitive distortions as part of sociomoral competence in driver training could produce safety benefits. However, follow-up research is 
needed to better understand the causes and processes of cognitive distortions in order to design driver-training programs that encourage the development of sociomoral competence.

\section{REFERENCES}

Barriga, A. Q., Morrison, E. M., Liau, A. K., \& Gibbs, J. C. (2001). Moral cognition: Explaining the gender difference in antisocial behavior. Merrill-Palmer Quarterly, 47(4), 532-562.

Beanland, V., Goode, N., Salmon, P.M., Lenné, M.G. (2013). Is there a case for driver training? A review of the efficacy of pre- and post-licence driver training. Safety Science, 51, 127-137.

Fuller, F. (1969). Concern of teachers: A developmental conceptualization. American Educational Research Journal, 6, 207-226.

Gibbs, J. C. (2003). Moral Development and Reality - Beyond the Theories of Kohlberg and Hoffman. London: Sage Publications Ltd

Gibbs, J. C. Barriga, A. Q., \& Potter, G. B. (2001). How I Think (HIT) Questionnaire. Champaign, IL: Research Press.

Gidron, Y., Slor, Z., Toderas, S., Herz, G., \& Friedman, S. (2015). Effects of psychological inoculation on indirect road hostility and simulated driving. Transportation Research Part F: Traffic Psychology and Behaviour, 30, 153-162. doi: https://doi.org/10.1016/j.trf.2015.01.012

Isler, R.B., Starkey, N.J., Sheppard, P. (2011). Effects of higher-order driving skill training on young, inexperienced drivers' on-road driving performance. Accident Analysis Prevention, 43, 1818-1827.

Lind, G. (2002). Ist Moral lehrbar? Ergebnisse der modernen moralpsychologischen Forschung [Can ethics be taught? Research findings from modern moral psychology] (2nd ed.). Berlin: Logos-Verlag.

Roelofs, E.C., \& Hirsch, P. (2017). Assessing Moral Reasoning, Cognitive Distortions and Driving Style in the Context of Post-license Young Driver Coaching. doi https://drivingassessment.uiowa.edu/previous-conferences/driving-assessment-2017/2017proceedings

Roelofs, E.C., \& Vissers, J.J.A.M. (2017). Rijopleiding op Maat (ROM). Resultaten van de praktijkproef in Noord-Limburg [Developmentally Adapted Driver Education: results of a pilot in North-Limburg]. Amersfoort: HaskoningDhv Nederland B.V.

Senserrick, T., Ivers, R., Boufous, S., Chen, H. Y., Norton, R., Stevenson, M., Van Beurden, E. Zask, A. (2009). Young driver education programs that build resilience have potential to reduce road crashes. Pediatrics, 124(5), 1287-1292.

Van Stam, M.A., Van der Schuur, W.A., Tserkezis, S., Van Vugt, E.S., Asscher, J.J., \& Gibbs, J.C. (2014). The effectiveness of EQUIP on sociomoral development and recidivism reduction: A meta-analytic study. Children and Youth Services Review, 38, 44-51. 